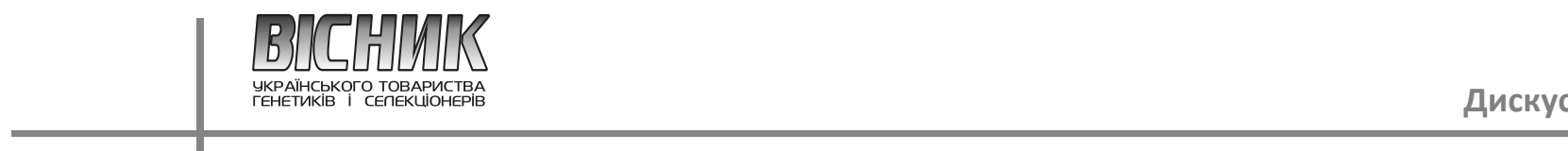 \\ ЭВОЛЮЦИЯ ДАРВИНИЗМА. НОВЫЙ ЭВОЛЮЦИОННЫЙ СИНТЕЗ: ОБЪЕДИНЕНИЕ ЭВОЛЮЦИОННОЙ ГЕНЕТИКИ И ГЕНЕТИКИ РАЗВИТИЯ
}

\author{
Ю. В. ВАГИН
}

Институт молекулярной биологии и генетики НАН Украины

Украина, 03143, Киев, ул. Акад. Заболотного, 150

e.mail: v.i.kashuba@imbg.org.ua

Представлены результаты синтеза эволюционной генетики и генетики развития, разъяснены причины кризиса эволюционной генетики и пути его преодоления, а также дано объяснение механизма видообразования высших организмов.

Ключевые слова: новый эволюционный синтез, эволюционная генетика, генетика онтогенеза, морфогенетическая программа, гены развития.

حак отмечалось в статье (Вагин, 2019), во второй половине XX века четко обоз-

Мначились узловые положения, характеризующие кризис эволюционной генетики или, иначе, синтетической теории эволюции (СТЭ). В рамках СТЭ не удалось дать удовлетворительное объяснение возникновению в процессе биологической эволюции сложных признаков организмов (Вагин, 2013; Гилберт, 2014; Кэрролл, 2015а). Не вписывались в её представления о равномерном течении эволюционного процесса палеонтологические данные, указывающие на разноскоростной характер фрилогенеза (ЕIdredge, Gould, 1972; Gould, 1977). В свою очередь данные, полученные на молекулярно-биологическом уровне, указывали на различную скорость эволюции белков (Кимура, 1985). Особо прискорбным для СТЭ обстоятельством явилась узость эмпирической базы, призванной подтвердить ведущую роль положительного отбора в процесах фрормирования, поддержания и реорганизации генетической структуры популяций (Вагин, 2013). Таким образом, ставилась под сомнение ведущая роль естественного отбора в историческом формообразовательном процессе и, тем самым, подрывались основы эволюционной генетики.

Преодоление указаного кризиса было напрямую связано с новым эволюционным синтезом (НЭС), заключавшимся в объединении эволюционной генетики и генетики развития (Вагин, 2010; Гилберт, 2014). Следствием выхода из него явилось изменение понятийного аппарата СТЭ, повлекшее за собой трансформацию её теоретических основ. Наряду с этим, в рамках НЭС наконец-то был получен убедительный ответ на вопрос о механизме видообразования высших организмов, который, по разным причинам (Вагин, 2019), не смогли дать авторы «Происхождения видов» и концепции биологического вида (Дарвин, 1935; Майр, 1947).

Стартом НЭС явились исследования (King, Wilson, 1975), показавшие, что различия между рядом структурных генов шимпанзе и человека, контролирующих гомологичные признаки этих видов, составляли около $1 \%$.

Необходимо отметить, что упомянутые виды принадлежат к различным родам семейства гоминидов (Schuh, Van Zandt Brower, 2009). Следовательно, полученные Кингом и Уилсоном результаты парадоксальным образом противоречили теоретическому канону (центральной догме) эволюционной генетики, гласившему: степень генетических различий между видами прямо пропорцианальна их фрилогенетической отдаленности.

Ю. В. ВАГИН, 2020

70 ISSN 2415-3680 (Online), ISSN 1810-7834 (Print). Вісн. Укр. тов-ва генетиків і селекціонерів. 2020, том 18, № 1-2 
Эволюция дарвинизма. Новый эволюционный синтез: объединение эволюционной генетики...

Исходя из него, один из столпов СТЭ Майр утверждал: «поиск гомологичных генов имеет смысл лишь в случае самых близкородственных организмов» (Майр, 1968).

По мнению (King, Wilson, 1975), существенные морфологические различия между шимпанзе и человеком, могли быть обусловлены видоспецифическим действием регуляторных генов. Отталкиваясь от данного предположения, Рэфф и Кофмен постулировали крайне продуктивную идею о наличии у высших организмов морфогенетических программ индивидуального развития, создающихся движущей формой положительного отбора на базе сравнительно небольшого количества регуляторных генов. Эти же гены, в результате мутаций, могли трансформировать морфогенетические программы индивидуального развития, что приводило к формированию альтернативных онтогенезов, в дальнейшем, используемых отбором в качестве материала для морфологической эволюции (Рэффф, Кофмен, 1986).

В свою очередь, структурные гены, по мнению Рэффа и Кофмена, играли ведущую роль в адаптивной модификации основного типа онтогенеза. Этот процесс находился под контролем мощного действия стабилизирующей формы дарвиновского отбора и осуществлялся путем «постепенной замены вариантных аллелей в соответствии с представлениями классической теории эволюции» (Рэффф, Кофмен, 1986). В данном случае под классической теорией эволюции Рэффр и Кофрмен подразумевали микроэволюционные процессы, протекающие в популяциях.

По мнению Гилберта, сложившаяся ситуация: «может привести к переоценке наших представлений о механизмах, лежащих в основе эволюционного изменения и разнообразия животных» (Гилберт, 1993). Дальнейший ход событий в полной мере подтвердил его предсказание. Результатом указанной переоценки явилась глубокая ревизия СТЭ, нашедшая свое выражение в новом эволюционном синтезе (Вагин, 2010; Гилберт, 2014; Кэрролл, 2015а).

Убедительные подтверждения, упомянутые выше идеи Рэффра и Кофмена, получили благодаря молекулярно-генетическим исследованиям последних лет. Результаты этих исследований выявили наличие более 100 генов развития регуляторных генов, контролирующих онтогенез животных (Гилберт, 2014; Кэрролл, 2015а). Первыми среди них были обнаружены гомеозисные гены Drosophila melanogaster (Гилберт, 2014).
Было установлено, что мутация лишь одного из этих генов приводила к заменам фенотипических признаков, известных как сериальные гомологи (Гилберт, 2014; Кэрролл, 2015а). Например, у дрозофилы на месте антенны развивалась нога, а на месте передних крыльев образовывались задние крылья. Выяснилось, что гомеозисные гены Drosophila melanogaster организованы в два кластера, расположенные по соседству на третьей хромосоме. Один из них, комплекс Bithorax, содержал три гена, контролирующие морфогенез задней части тела дрозофилы. Другой, комплекс Antennapedia, состоял из пяти генов, определяющих развитие передней части её тела. Порядок расположения генов в кластерах соответствовал порядку расположения контролируемых ими признаков. При этом было установлено, что каждый из восьми генов содержал идентичную последовательность ДНК, насчитывающую 180 оснований. Данная последовательность кодировала 60аминокислотный белковый домен, входящий в состав всех белков указанных генов развития. Её назвали гомеобоксом, а кодируемый ею белковый домен - гомеодоменом (Гилберт, 2014). Необходимо также отметить, что хотя каждый из гомеозисных генов оказывает специфическое влияние на определённый признак, все их продукты гомеозисные белки - имеют сходные функции; в дальнейшем гомеозисные гены с гомеобоксами данного типа стали именовать Нох-генами (Гилберт, 2014; Кэрролл, 2015а). Позднее было установлено, что у членистоногих и позвоночных, Нох-гены на ранних стадиях развития определяют функциональную специфиику сомитов эмбрионов в направлении от головы к хвосту (Гилберт, 2014).

Проведенный у представителей различных видов анализ выявил высокую степень гомологии гомеобоксов, что указывало на их древнее происхождение и эволюционный консерватизм, обусловленный важной ролью гомеобоксов в онтогенезе всех представителей царства животных (Гилберт, 2014; Кэрролл, 2015а).

К наиболее известным генам развития, наряду с Нох-генами, принадлежат гены eyeless, Aniridia, Smalleye, Distal-less (DII), tinman и ряд других (Гилберт, 2014; Кэрролл 2015а; Кэрролл 2015б).

Ген eyeless вызывает у мутантов Drosophila melanogaster полное отсутствие глаз. У человека известен его аналог - ген Aniridia. Его мутация приводит к уменьшению размеров глаз или к исчезновению их радужной оболочки. У мыши подобный ген известен как Small eye. Его мутация 


\section{Ю. В. Вагин}

также вызывает аномалию или полное отсутствие глаз. Было установлено, что индукция экспрессии гена eyeless на крыльях или ногах дрозофил, приводила к возникновению на них элементов глаза. Следовательно, ген eyeless являлся ключевым для развития глаза и, исходя из этого, был определён как мастер-ген. В свою очередь, экспериментально индуцированная экспрессия гена мыши Small eye в ряде мест тела дрозофилы, не связанных с формированием глаз, также приводила к образованию элементов глаза, но дрозофрилы, а не мыши. Полученные результаты определённо указывали на то, что структура глаза животных определялась не происхождением контролирующего её развитие гена, а контекстом материала наследственности; в данном случае видовой принадлежностью генома организмахозяина (Гилберт, 2014). В дальнейшем гены развития eyeless, Aniridia, Small eye получили общее название - Рах-6. На сегодня установлено, что ген Рах-6 контролирует развитие самых разных типов глаз - начиная от простых, как у плоских червей, и заканчивая сложными, как у насекомых или позвоночных (Гилберт, 2014; Кэрролл, 2015a). Ген DIl участвует в формировании дистальных участков конечностей у всех членистоногих и позвоночных. Он, наряду с геном еуеless, также является мастер-геном, вовлечённым в создание весьма разнообразных структур, общим свойством которых является их связь с туловищем животных. Ген tinman контролирует морфогенез сердца у Drosophila melanogaster и других членистоногих. Его функциональный и структурный гомолог, ген развития NK2, обнаружен у позвоночных. Таким образом, членистоногие и позвоночные используют для формирования своих сердец гомологичные гены: tinman и NK2 (Гилберт, 2014).

Продукты указанных выше генов развития входят в состав четырёх семейств белков: Нох, Pax-6, DII и Tinman. Они содержат гомеодомены и являются ДНК-связывающими белками. При этом данные гомеодомены имеют выраженное сходство, но не идентичны, что проявляется в их функциональной специфичности при связывании с ДНК (Кэрролл 2015а).

Итак, установлено, что в морфогенезе всех типов глаз, конечностей и сердец у представителей царства животных задействуются одни и те же гены развития. Следовательно, данные гены являются древними, эволюционно консервативными, гомологичными, входят в состав морфогенетических программ представителей современных видов животных и впервые использовались в онтогенезе их отдаленных предков (Гилберт, 2014; Кэрролл 2015а; Кэрролл 2015б). В связи с этим встают правомочные вопросы. Если наборы генов развития в царстве животных на заре их эволюции и в настоящее время практически совпадают, то каким образом между ними возникли выраженные морфологические различия? В чём заключается разгадка этого парадокса?

Перечисленные ранее гены входят в состав наиболее известной десятки генов, определяющих развитие животных. Они, наряду с другими генами развития, интегрированы в состав морфогенетических программ, контролирующих онтогенез у представителей современных видов, порой, находящихся друг от друга на довольно значительных эволюционных расстояниях (Гилберт, 2014; Кэрролл, 2015а). Выяснилось, что инструкции, определяющие время и место экспрессии отдельных генов развития, содержатся в созданных естественным отбором генных переключателях (Кэрролл, 2015а). Они располагаются в 2-3 \% «темной материи» генома, основной частью которой является «мусорная» ДНК, накопившаяся в процессе миллионов лет эволюции (Кэрролл, 2015а; Кэри, 2016). Самое важное свойство генных переключателей - способность контролировать нюансы экспрессии отдельных генов развития. Генные переключатели рассредоточены по всему геному и, по сути, являются кодом, в соответствии с которым воспроизводятся и эволюционируют фенотипы животных различных видов. При этом они являются автономными устройствами по обработке информации (Кэрролл, 2015а). Таким образом, в результате их мутаций изменяется ход развития лишь одного, контролируемого ими признака, а морфогенез остальных признаков остаётся неизменным. Далее вступает в действие естественный отбор, определяющий селективную ценность указанных наследственных изменений. По результатам его оценки, возникшие de novo мутации генных переключателей, либо элиминируются, либо фиксируются в составах генофондов популяций различных видов.

Исходя из вышеизложенного, можно заключить, что генные переключатели являются ключеВыми фракторами, контролирующими, наряду с естественным отбором, процессы онтогенеза и филогенеза животных. В своей совокупности они объединяют уникальные, для каждого вида, инструкции, позволяющие формировать и поддерживать морфогенез его особей с помощью единого набора генов развития. В свою очередь материалом, используемым в процессе морфологической эволюции, являются наследственные изменения 
Эволюция дарвинизма. Новый эволюционный синтез: объединение эволюционной генетики...

самих генных переключателей, трансформирующие видовой морфогенез особей в пределах отдельно взятых признаков; при этом гены развития сохраняют стабильность своей структуры.

Именно в этом кроется разгадка указанного выше парадокса. Именно здесь дан убедительный ответ на вопрос о механизме видообразования высших организмов.

Далее рассмотрим ход биологической эволюции в рамках Нового Эволюционного Синтеза. Установлено, что он неравномерен (Eldredge, Gould, 1972; Gould, 1989) и характеризуется продолжительными, по геологической шкале времени, этапами относительного постоянства видов (обусловленными адаптивной эволюцией, контролируемой стабилизирующим отбором) и менее продолжительными этапами их трансформации (обусловленными морфологической эволюцией, контролируемой движущим отбором). Действие стабилизирующей и движущей фрорм отбора определяет специфику поэтапного хода фрилогенеза, однако, на каждом из этапов имеет место также их взаимное влияние на эволюционный процесс. В конечном счёте, результат филогенеза обусловливается взаимодействием указанных фрорм отбора с конкретными экологическими фракторами. При этом морфологическая эволюция селективная трансформация морфогенетических программ - обусловливается, в большей мере, взаимодействием с биотической средой. В свою очередь с косной средой, в частности, с градуализмом, прочно коррелирует адаптивная эволюция - селективное поддержание и коррекция морфогенетических программ. Говоря иначе, есть биотические адаптации, как выражение морфологической эволюции, и есть градуалистические адаптации, как выражение адаптивной эволюции; любая из указанных фрорм эволюции адаптивна, поскольку контролируется естественным отбоpom.

Итак, морфологическая эволюция контролируется движущим отбором. При этом эволюционные изменения происходят путем модификации наследственно детерминированных программ онтогенеза животных, базирующихся на сравнительно небольшом количестве генов развития (Рэфф, Кофммен, 1986). Указанные гены функционируют опосредованно, через генетические переключатели, определяя, в том числе, альтернативные состояния или пути их индивидуального развития (Вагин, 2013; Кэрролл, 2015а). Подобный механизм управления онтогенезом способен обеспечивать достаточно быстрые, по геологической шкале времени, морфологические измене- ния, приводящие к возникновению новых планов (типов) строения организмов (Рэффр, Кофрмен, 1986; Вагин, 2013; Гилберт, 2014). В свою очередь адаптивная эволюция находится под мощным контролем стабилизирующей формы положительного отбора и осуществляется путем «постепенной замены вариантных аллелей структурных генов в соответствии с представлениями классической теории эволюции» (Рэффр, Кофрмен, 1986). Следовательно «неспешный» ход адаптивной эволюции, характерный, по геологической шкале, для относительно длительных промежутков времнени (Eldredge, Gould, 1972; Gould, 1989), находит удовлетворительное объяснение в рамках представлений о микроэволюции, осуществляемой в популяциях путем селекции структурных генов (Рэффр, Кофмен, 1986). Таким образом, подход, основанный на различиях ролей структурных генов и генов развития в процессе филогенеза, позволил дать удовлетворительное объяснение механизму возникновения у животных новых морфологических признаков и разноскоростному характеру их эволюции.

Сущность модернизации парадигмы эволюционной генетики, осуществленной НЭС, заключается в разграничении ролей структурных и регуляторных генов в эволюционном процессе, а также в том, что в основе морфологической эволюции лежит древнейшая программа морфогенеза. В тоже время сам процесс филогенеза осуществляется путем ее селективной трансформации. Из этого следует, что НЭС трансформировал «взгляд» СТЭ на ход и «управление» историческим развитием организмов. Таким образом, был преодолён кризис, порожденный ограниченностью некоторых теоретических положений СТЭ (Вагин, 2019). При этом сохранился основополагающий постулат классического дарвинизма, о ведущей роли отбора в эволюции организмов, подразумевающий действие естественного отбора на уровне фенотипов, нацеленное на преобразование наследственной программы индивидуального развития организмов, как ответа на изменяющиеся экологические требования (Вагин, 2013).

За последние годы заметно расширилась эмпирическая база, подтверждающая ведущую роль отбора в формировании генетического полиморфизма популяций целого ряда видов, в том числе омаров, креветок, пауков, змей, пятнистых бабочек, мешотчатых прыгунов, ягуаров и т. д. (Кэрролл, 2015б). В основном это явилось следствием разработки и внедрения в практику биологических исследований новей- 


\section{Ю. В. Вагин}

ших инструментальных методов изучения первичной структуры ДНК. В результате этого получены дополнительные сведения, касающиеся адаптивних изменений многих структурних генов (Кэрролл 2015а). Благодаря этим сведениям, найдено также решение одной из важнейшей задач эволюционной биологии: естественной систематизации видов, основанной на данных анализов первичной структуры геномов представляющих их особей (Кэрролл 2015а; Кэрролл 2015б). Молекулярная систематика, построенная на анализе первичной структуры генов, позволяет разграничить тождественные адаптивные изменения у представителей систематически далёких видов, возникших в процессе их приспособления к сходным экологическим условиям, от тождественных адаптивних изменений у представителей близкородственных видов, связанных с их общей генеалогией (Кэрролл, 2015б).

О необходимости создания подобной системы видов, построенной на основе естественной истории их возникновения, писал ещё Ламарк, указывавший на фундаментальные недостатки систематики К. Линнея, построенной на анализе сугубо морфологических признаков организмов (Ламарк, 1935).

Итак, Новый Эволюционный Синтез позволил раскрыть механизм возникновения у животных, в ходе их исторического развития, сложных признаков, получить доказательства в пользу разноскоростного характера их филогенеза. Помимо этого были установлены дополнительные фракты, подтверждающие ведущую роль положительного отбора в процессах формирования, поддержания и реорганизаци генетической структуры их популяций. В результате удалось преодолеть обозначенный в начале статьи кризис СТЭ, сохранив при этом основополагающий постулат классического дарвинизма о ведущей роли естественного отбора в контроле над эволюционным процессом.

Завершая рассмотрение эволюции дарвинизма, основополагающего учения современной биологии, представим её основные вехи. Первоначально дарвинизм прочно опирался на учение о естественном отборе, как ведущем факторе эволюции. Оно являлось главным теоретическим постулатом дарвинизма. Однако в шестом, последнем прижизненном издании «Происхождения видов», Дарвин, в силу ряда причин, пожертвовал естественным отбором в угоду ламаркизму. Это явилось причиной деградации дарвинизма, приведшей к тому, что в начале XX века большинство биологов, хотя и принимало концепцию эволюции, но мало кто из них считал, что естественный отбор является её основной движущей силой. В качестве таковой господствовали «определенная» изменчивость Ламарка, ортогенез и видовые мутации Хуго де Фриза (Вагин, 2018). Наконец в 1926 году началось объединение дарвинизма и генетики, из которого выросла синтетическая теория эволюции. В рамках данной теории естественный отбор вернул себе роль главного фактора эволюции (Вагин, 2019). В середине 70-х годов стартовал синтез эволюционной генетики и генетики развития. Его главным научным результатом явился фракт древнего происхождения наследственных программ развития организмов. Выяснилось, что селективная модификация этих программ в процессе фрилогенеза приводила к созданию новых форм животных, то есть являлась магистральным путем их биологической эволюции. Таким образом, благодаря объединению эволюционной генетики и генетики развития был раскрыт механизм морфологической эволюции, действующий в процессе видообразования. А эволюция самого дарвинизма, начавшаяся с публикации «Происхождения видов», до настоящего времени определяет лицо современной биологи. Основное достижение НЭС - установление факта древнего происхождения наследственных программ развития, используемых, путём их селективной модификации, в процессе онто- и филогенеза для создания новых форм животных.

Выход в свет величайшего научного труда Дарвина «Происхождения видов...» пролившего свет на механизм биологической эволюции. Открытие заново, на рубеже XIX и XX веков, законов Менделя, приведшее к фрормированию современной генетики. Стартовавшее 90 лет назад объединение дарвинизма и генетики. Разграничение эволюционных ролей структурных генов и генов развития, явившееся следствием НЭС. Эти события в существенной мере определили путь формирования и лицо современной биологии.

\section{Список литературы:}

1. Vagyn Yr. V. Krisis neodarvinisma I ego preodolenie putem novogo evolyucionnogo sinteza, Fakt. Eksper. Evol. Org.: Mat. Nauk. Konf. K. : Agrana nauka, 2010. C. 7-11. [in Russian] / Вагин Ю. В. Кризис неодарвинизма и его преодоление путем нового эволюционного синтеза. Фактори експериментальної еволюції організмів: Матеріали науково їконференції. К. : Аграрна наука, 2010. С. 7-11. 
2. Vagyn Yr. V. Polozitelnuiy prenatalnuiy otbor u placentarnuh mlekopitauschih (Eutheria). K. : Naukova dumka, 2013. 60 s. [in Russian] / Вагин Ю. В. Положительный пренатальный отбор у плацентарних млекопитающих (Eutheria). Киев: Наукова думка, 2013. 160 с.

3. Vagyn Yr. V. Evolution of Darwinism. The classical stage: 1859-1926 years. Visn. Ukr. tov. genet. sel. 2018. V. 16 (1). P. 69-74. [in Russian] / Вагин Ю. $B$. Эволюция дарвинизма. Классический этап. 1859-1926 годы. Вісник українського товариства генетиків і селекціонерів. 2018. Т. 16(1). С. 69-74.

4. Vagyn Yr. V. Evolution of Darwinism. Synthetic theory of evolutions. Visn. Ukr. tov. genet. sel. 2019. V. 17(1). P. 51-56. [in Russian] / Вагин Ю. В. Эволюция дарвинизма. Синтетическая теория эволюции: 1926-1975 годы. Вісник українського товариства генетиків і селекціонерів. 2019. Т. 17(1). C. $51-56$.

5. Gilbert S. Bilogiya razvitiya. M. : ISBN, 2014. 838 c. [in Russian] / Гилберт С. Биология развития. М. : ISBN, 2014. $838 \mathrm{c}$.

6. Darwin Ch. On the Origin of Species by Means of Natural Selection, or the Preservation of Favoured Races in the Struggle for Life. Sixth edition, with additions and corrections. London (GB): John Murray, 1872. 562 р. / Дарвин Ч. Происхождение видов. М., Л. : ОГИЗ - СЕЛЬХОЗГИЗ, 1935. 630 с.

7. Kimura M. The Neutural Theory of Molecular Evolution. Cambridge (USA): Cambridge University Press, 1983. 385 р. / Кимура М. Молекулярная эволюция: теория нейтральности. М. : Мир, 1985. 394 с.

8. Kery N. Mysornaya DNK. Puteshestvie $v$ temnuyu materiyu genoma. M. : Laboratoriya znaniy, 2016. 336 c. [in Russian] / Кэри Н. Мусорная ДНК. Путешествие в темную материю генома. М. : Лаборатория знаний, 2016. 336 с.

9. Kerroll Sh.a. Beskonechnoe chislo samux prekrasnux form/ Novayia nauka evo-devo I evoluciya carstva zivotnux. M.: CORPUS, 2015. 432 c. [in Russian] / Кэрролл Ш.а. Бесконечное число самых прекрасных форм. Новая наука эво-дево и эволюция царства животных. M. : CORPUS, 2015. $432 \mathrm{c}$.

10. Kerroll Sh.б. Prisposobitsyu i vuzit! DNK kak letopis evolucii. M. : CORPUS, 2015. 368 c. [in Russian] / Кэрролл Ш.б. Приспособиться и выжить! ДНК как летопись эволюции. М. : CORPUS, 2015. 368 с.

11. Lamark J.-B. Izbrannue proizvedenia $v$ dvuh tomah. T. 1. - Izd-vo AN SSSR, 1955. - 333 s. [in Russian] / Ламарк Ж.-Б. Философия зоологии Т. 1. М., Л. : Биомедгиз, 1935. 331 с.

12. Mayr E. Systematics and the Origin of Species. N. Y. (USA): Columbia Univ. press, $1942 .-486$ р. / Майр Э. Систематика и происхождение видов. М. : Иностранная литература, 1947. 504 c.

13. Mayr E. Evoluciya. Jour. Vses. Him. Ob-va. Im. D. I. Mendeleeva. 1980. V. 25(3). C. 266-277. [in Rus- sian] / Майр Э. Эволюция. Ж. Всес. Хим. Об-ва им. Д. И. Меделеева. 1980. Т. 25(3). С. 266-277.

14. Eldredge N., Gould S. J. Punctuated equilibria: an alternative to phyletic gradualism. In book: Models in Paleobiology. San Francisco (USA): Freeman Cooper, 1972. P. 82-115.

15. Gould S. J. Ontogeny and Phylogeny. Cambridge (USA): Harvard University Press, 1977. 501 p.

16. Gould S. J. Wonderful Life: The Burgess Shale and the Nature of History. New York (USA): W. W. Norton \& Company, 1989. 475 p.

17. Schuh R. T., A. V. Z. Brower. Biological Systematics: Principles and Applications. Comstock Pub. Associates (USA): Cornell University Press, 2009. 311 p.

Стаття надійшла до редакції 10.03.2020. Прийнята до друку 16.04.2020

\section{ЕВОЛЮЦІЯ ДАРВІНІЗМУ. НОВИЙ ЕВОЛЮЦІЙНИЙ СИНТЕЗ: ОБ'ЄДНАННЯ ЕВОЛЮЦІЙНОÏ ГЕНЕТИКИ I ГЕНЕТИКИ РОЗВИТКУ}

\section{Ю. В. Вагін}

Інститут молекулярної біології і генетики НАН України Україна, 03143, Київ, вул. Академіка Заболотного, 150 e.mail: v.i.kashuba @imbg.org.ua

Представлено результати синтезу еволюційної генетики і генетики розвитку, роз'яснено причини кризи еволюційної генетики та шляхи його подолання, а також дано пояснення механізму видоутворення вищих організмів.

Ключові слова: новий еволюційний синтез, еволюційна генетика, генетика онтогенезу, морфогенетична програма, гени розвитку.

\section{EVOLUTION OF DARWINISM. A NEW EVOLUTIONARY SYNTHESIS: COMBINING EVOLUTIONARY GENETICS AND DEVELOPMENT GENETICS.}

\author{
Yu. V. Vagyn
}

Institute of Molecular Biology and Genetics NAS of Ukraine Ukraine, 03143; Kyiv, Akademika Zabolotnogo Str., 150 e.mail: v.i.kashuba @imbg.org.ua

The results of the synthesis of evolutionary genetics and developmental genetics are presented, the causes of the crisis of evolutionary genetics and ways to overcome it are explained, and the mechanism of speciation of higher organisms is explained.

Keywords: new evolutionary synthesis, evolutionary genetics, genetics of ontogenesis, morphogenetic program, developmental genes. 